\title{
QUALITY OF BASIC CHILD IMMUNIZATION PROGRAM ACCORDING TO MINIMUM SERVICE STANDARD AT COMMUNITY HEALTH CENTER
}

\author{
Chamelia Anggraeni Probo Sitihajar1), Dumilah Ayuningtyas²) \\ 1)Quality of Health Services, Faculty of Public Health, Universitas Indonesia \\ ${ }^{2)}$ Department of Health Administration Policy, Faculty of Public Health, \\ Universitas Indonesia
}

\begin{abstract}
Background: Universal immunization of children against six preventable diseases (tuberculosis, diphtheria, pertussis, tetanus, polio, and measles) is vital to reduce childhood mortality and morbidity across the world. Although immunization coverage in Indonesia is increasing year by year, it still falls short of the WHO and UNICEF's goals as stated in their Global Immunization Vision and Strategy: to reach 90\% of children under the age of one with routine immunization nationwide, and at least $80 \%$ in every district in the country by the year 2020. Almost half (46.64\%) of children in Indonesia did not receive complete immunization in 2012. This study aimed to examine the quality of basic child immunization program according to minimum service standard at Community Health Center.

Subjects and Method: This was a qualitative study with Rapid Assesment Procedure approach in July 2019. Total of 14 informants were selected for this study including: chief of individual health unit, program director, and 12 program managers. The study theme was completeness and quality of basic child immunization program according to minimum services standard. The data were collected by in-depth interview, focus group discussion, and document review. The data were analyzed by content analysis.

Results: Input and process of child immunization program were not in accordance with the minimun service standard set by the Ministry of Health. The number of immunization workers was lacking, training was uneven, work rotation was too fast, infant data was incompatible, health workers neglected to wash their hands, and staff knowledge about vaccine-associated adverse events and anaphylatic shock was uneven. The child immunization target output has been achieved.

Conclusion: Community health center have not maximally performed complete basic child immunization service in accordance with the Minimum Service Standard set by the Indonesian Ministry of Health in terms of input and process. The child immunization target output has been achieved.
\end{abstract}

Keywords: quality, complete immunization, minimum service standard

\section{Correspondence:}

Chamelia Anggraeni P S. Quality of Health Services, Faculty of Public Health, Universitas Indonesia. Email: chameliaaps12@gmail.com. Mobile: 081284200488 